\title{
Preventive Effects of Lycopene-Enriched Tomato Wine against Oxidative Stress in High Fat Diet-Fed Rats
}

\author{
A-Young Kim ${ }^{1,2}$, Seon-Min Jeon ${ }^{1,2}$, Yong-Jin Jeong ${ }^{3}$, Yong Bok Park ${ }^{4}$, \\ Un Ju Jung ${ }^{1,2}$, and Myung-Sook Choi ${ }^{1,2 \dagger}$ \\ ${ }^{1}$ Department of Food Science and Nutrition, Kyungpook National University, Daegu 702-701, Korea \\ ${ }^{2}$ Center for Food and Nutritional Genomics Research, Kyungpook National University, Daegu 702-701, Korea \\ ${ }^{3}$ Department of Food Science and Technology, Keimyung University, Daegu 704-701, Korea \\ ${ }^{4}$ School of Life Sciences and Biotechnology, Kyungpook National University, Daegu 702-701, Korea
}

\begin{abstract}
This study was performed to investigate the antioxidant mechanism of tomato wine with varying lycopene content in rats fed a high fat diet (HFD). Male Sprague-Dawley rats were randomly divided into five groups ( $\mathrm{n}=10$ per group) and fed an HFD (35\% of total energy from fat) plus ethanol $(\mathbf{7 . 2 \%}$ of total energy from alcohol), tomato wine with varying lycopene content $(0.425 \mathrm{mg} \%, 1.140 \mathrm{mg} \%$ or $2.045 \mathrm{mg} \%$ lycopene) or an isocaloric control diet for 6 weeks. Mice fed HFD plus ethanol significantly increased erythrocyte hydrogen peroxide and thiobarbituric acid reactive substances (TBARS) levels with increases in activities of erythrocyte antioxidant enzymes such as superoxide dismutase (SOD), catalase (CAT), glutathione peroxidase (GSH-Px) and glutathione reductase (GR) compared to pair-fed rats. Supplementation of tomato wine with varying lycopene content decreased ethanol-mediated increases of erythrocyte lipid peroxidation and antioxidant enzyme activities in HFD-fed rats, and tomato wine with higher lycopene appeared to be more effective. Tomato wine also dose-dependently lowered TBARS levels with decreased pro-oxidant enzyme, xanthine oxidase (XOD) activity in plasma of HFD-fed rats. In contrast to erythrocytes, the inhibitory effects of tomato wine on hepatic lipid peroxidation were linked to increased hepatic antioxidant enzymes (SOD and CAT) and alcohol metabolizing enzyme (alcohol dehydrogenase and aldehyde dehydrogenase) activities. There were no significant differences in hepatic XOD and cytochrome P450-2E1 activities among the groups. Together, our data suggest that tomato wine fortified with lycopene has the potential to protect against ethanol-induced oxidative stress via regulation of antioxidant or pro-oxidant enzymes and alcohol metabolizing enzyme activities in plasma, erythrocyte and liver.
\end{abstract}

Key words: antioxidant effects, a high fat liquid diet, lipid peroxidation, lycopene, tomato wine

\section{INTRODUCTION}

Chronic consumption of alcoholic beverages is a major cause of liver injury such as serious fatty liver, cirrhosis and cancer (1). Ethanol-induced oxidative stress is known to play a major role in the mechanisms by which ethanol produces liver injury $(2,3)$. In particular, the combination of a high fat diet (HFD) and ethanol causes an increase in lipid peroxidation, most likely as a consequence of a decrease in antioxidant defense induced by an HFD and an increase in reactive oxygen species (ROS) production induced by ethanol (4). However, epidemiological evidence suggests that some alcoholic beverages, such as red wine, reduce the risk of coronary heart disease and may have a protective effect on the liver $(5,6)$.

It has been shown that dietary intake of tomatoes and tomato-based products such as tomato juice and tomato paste can decrease risk of chronic diseases such as cardiovascular diseases and cancer (7), but there are no studies on the potential effects of tomato wine. The beneficial properties of tomato appear to be related to the antioxidant content, particularly lycopene and $\beta$-carotene, which may play a role in inhibiting reactions mediated by ROS (8). Lycopene, a red carotenoid pigment found in tomatoes and other fruits or vegetables, is an isomer of $\beta$-carotene but does not have provitamin A activity. It is an acyclic, highly unsaturated, straight chain hydrocarbon with thirteen double bonds (11 conjugated, 2 nonconjugated) $(9,10)$ (Fig. 1). Because of its high number of conjugated double bonds, it is one of the most potent

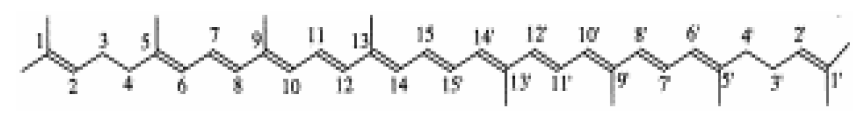

Fig. 1. Structure and numbering of lycopene. 
antioxidants among dietary carotenoids. It is reported that lycopene exhibits higher singlet oxygen quenching ability than $\beta$-carotene or $\alpha$-tocopherol (11) and it may reduce the risk of atherosclerosis and cancer by preventing the oxidative damage of biomolecules including lipids, proteins and DNA (12-16).

Furthermore, several studies suggest that lycopene can decrease alcohol-induced oxidative stress $(17,18)$. Lycopene decreases alcohol-induced hydrogen peroxide and glutathione levels in HepG2 cells overexpressing cytochrome P450-2E1 (CYP2E1) (17). An epidemiological study also reported an inverse association between lycopene and alcohol-induced liver damage in moderate and heavy drinkers ( $>25 \mathrm{~g}$ of ethanol/day) (18). However, several studies showed the antioxidant and pro-oxidant properties of lycopene may be dose-dependent $(19,20)$. Veeramachaneni (21) reported that supplementation of lycopene at high dose $(3.3 \mathrm{mg} / \mathrm{kg} \mathrm{BW} /$ day $)$, but not at lower dose $(1.1 \mathrm{mg} / \mathrm{kg} \mathrm{BW} /$ day $)$, induced hepatic oxidative stress and inflammation in alcohol-fed rats.

In light of these collective data, we hypothesized that tomato wine containing varying lycopene may protect or exacerbate oxidative stress induced by high fat and alcohol intake. Thus, we evaluated the effects of tomato wine containing low, medium and high lycopene content on oxidative stress and ethanol-induced hepatic biomarkers in HFD-fed rats.

\section{MATERIALS AND METHODS}

\section{Materials}

Tomatoes were purchased from a local market (Daegu, Korea). D,L-cystein, D,L-methionine, cholin bitrate, and xanthan gum were purchased from Sigma Chemical Co. (St. Louis, MI, USA).

\section{Supplement preparation}

Full-mature rasped tomato $(1 \mathrm{~kg})$ without stem was fortified with sugar to be $22^{\circ}$ Brix, initial acidity was revised to $0.45 \%$ by using tartaric acid, S. bayanus Lalvin EC-1118 (5\%) was inoculated as starter and then static culture was cultivated in an incubator at $25^{\circ} \mathrm{C}$ for 3 days. After alcohol fermentation, the solution was filtered through non-woven fabric and centrifuged at 13,000 rpm for $5 \mathrm{~min}$, which resulted in a supernatant of tomato wine with a low lycopene content $(4.25 \mathrm{mg} \%)$. Tomato wine with medium and high lycopene contents (11.40 $\mathrm{mg} \%$ and $20.45 \mathrm{mg} \%$, respectively) was made by adding either $10 \%(\mathrm{w} / \mathrm{v})$ tomato puree for medium lycopene levels or $20 \%(\mathrm{w} / \mathrm{v})$ tomato puree for high lycopene levels. The three types of tomato wine with varying lycopene content were used for the dietary intervention.

\section{Experimental animals}

Fifty male Sprague-Dawley rats (4-week-old) weighing between 80 and $100 \mathrm{~g}$ were purchased from the Central Lab. Animal Inc. (Seoul, Korea). The animals were all individually housed in stainless steel cages in an air-conditioned room with controlled temperature (20 $\sim 23^{\circ} \mathrm{C}$ ) and automatic lighting (alternating a $12 \mathrm{hr}$ period of light and dark). All of the rats were treated in strict accordance with the Kyungpook National University guidelines for the care and use of laboratory animals.

\section{Experimental design}

All rats were fed pellets of commercial chow for 1 week after arrival. The rats were randomly divided into five groups ( $\mathrm{n}=10$ per group), which were assigned to one of five dietary categories; a high fat liquid diet $(35 \%$ of total energy) plus ethanol ( $7.2 \%$ of total energy) (ethanol control, EC), a normal diet that includes the same amount of fat (35\% of total energy) and energy as each ethanol group consumed in the previous day (pair-fed control, PC), a high fat liquid diet (35\% of total energy) plus low lycopene $(0.425 \mathrm{mg} \%)$ tomato wine (TW-LL, $7.2 \%$ of total energy), a high fat diet (35\% of total energy) plus medium lycopene $(1.140 \mathrm{mg} \%)$ tomato wine (TW-ML, $7.2 \%$ of total energy), a high fat diet (35\% of total energy) plus high lycopene $(2.045 \mathrm{mg} \%)$ tomato wine (TW-HL, 7.2\% of total energy) for $6 \mathrm{wk}$. The composition of the experimental diet was based on the modified Liber-DeCarli liquid diet (22) as shown in Table 1. Each group was given the modified liquid diet $(\sim 100 \mathrm{~mL} /$ day). Ethanol was introduced gradually into the diet starting from $5 \%$ of energy during the first and second day, increasing to $6 \%$ of energy during the third and fourth day and was finally served to $7.2 \%(\mathrm{w} / \mathrm{v})$ from the fifth day. The rats in the PC group received an ethanol-free normal liquid diet containing dextrin-maltose instead of ethanol.

\section{Sample preparation}

At the end of the experimental period, the rats were anesthetized with ketamin-HCL following a $12 \mathrm{hr}$ fast. Blood was drawn from the inferior vena cava into heparin-coated tubes to determine plasma biomarkers. The liver was removed, rinsed with physiological saline, and weighed immediately. All samples were stored at -70 ${ }^{\circ} \mathrm{C}$ until biomarkers analysis.

The preparation of the enzyme source in the erythrocytes was as follows: after the heparin treated blood samples were centrifuged at $1,000 \times \mathrm{g}$ for $15 \mathrm{~min}$ at $4^{\circ} \mathrm{C}$, the plasma and buffy coat were carefully removed. The separated cells were then washed three times by resuspension in a $0.9 \% \mathrm{NaCl}$ solution and recentrifuged. The washed cells were lysed in an equal volume of water 
Table 1. Composition of experimental and control diets ${ }^{1)}$ $(\mathrm{g} / \mathrm{L} / 1,000 \mathrm{cal})$

\begin{tabular}{|c|c|c|c|c|c|}
\hline Groups & $\mathrm{EC}$ & $\mathrm{PC}$ & TW-LL & TW-ML & TW-HL \\
\hline Casein & 41.4 & 41.4 & 41.4 & 41.4 & 41.4 \\
\hline L-Cystein & 0.5 & 0.5 & 0.5 & 0.5 & 0.5 \\
\hline D,L-Methionine & 0.3 & 0.3 & 0.3 & 0.3 & 0.3 \\
\hline Corn oil & 8.5 & 8.5 & 8.5 & 8.5 & 8.5 \\
\hline Olive oil & 31.3 & 31.3 & 31.3 & 31.3 & 31.3 \\
\hline Dextrin maltose $^{2)}$ & 97.2 & 115.2 & 97.2 & 97.2 & 97.2 \\
\hline Cholin bitartrate & 0.53 & 0.53 & 0.53 & 0.53 & 0.53 \\
\hline Fiber & 10.0 & 10.0 & 10.0 & 10.0 & 10.0 \\
\hline Xanthan gum & 3.0 & 3.0 & 3.0 & 3.0 & 3.0 \\
\hline Vitamin mixture & 2.55 & 2.55 & 2.55 & 2.55 & 2.55 \\
\hline Mineral mixture ${ }^{4)}$ & 9.0 & 9.0 & 9.0 & 9.0 & 9.0 \\
\hline Ethanol & 10.0 & - & - & - & - \\
\hline TW-LL & - & - & 100 & - & - \\
\hline TW-ML & - & - & - & 100 & - \\
\hline TW-HL & - & - & - & & 100 \\
\hline
\end{tabular}

${ }^{1)}$ The liquid diet was mixed in $1 \mathrm{~L}$ of distilled water.

${ }^{2)}$ The ethanol in the ethanol diet was replaced with additional dextrin maltose in the pair-fed group.

${ }^{3)} \mathrm{AIN}-76$ vitamin mixture.

4) AIN-76 mineral mixture.

EC, ethanol control; PC, pair-fed control; TW-LL, tomato wine with low lycopene content; TW-ML, tomato wine with medium lycopene content; TW-HL, tomato wine with high lycopene content.

and mixed thoroughly. The hemoglobin concentration was estimated in an aliquot of the hemolysate, using a commercial assay kit (No. 525-A, Sigma Chemical Co.). An appropriate dilution of the hemolysate was then prepared from the erythrocytes suspension by the addition of distilled water to estimate catalase (CAT) and glutathione peroxidase (GSH-Px) activities. Hemoglobin was removed by precipitation with chloroform : ethanol as follows (23): $0.2 \mathrm{~mL}$ of an ethanol : choloroform (3:5, $\mathrm{v} / \mathrm{v})$ mixture was added to an aliquot of the hemolysate cooled in ice. This mixture was stirred constantly for $15 \mathrm{~min}$ and then diluted with water. After centrifugation for $10 \mathrm{~min}$ at $1,600 \times g$, the pale yellow supernatant was separated from the protein precipitate and used to assay superoxide dismutase (SOD).

The enzyme source fraction in the liver was prepared according to the method developed by Hulcher and Oleson (24), with slight modification. A 20\% (w/v) homogenate was prepared in a buffer containing $0.1 \% \mathrm{M}$ triethanolamine, $0.02 \mathrm{M}$ EDTA and $2 \mathrm{mM}$ dithiothreitol $(\mathrm{pH}$ 7.0). This homogenate was centrifuged at $600 \times g$ for $10 \mathrm{~min}$ to discard any cellular debris. The supernatant was then centrifuged at $10,000 \times g$ for $20 \mathrm{~min}$ to isolate the mitochondrial pellet. Subsequently, the supernatant was ultracentrifuged twice at $100,000 \times \mathrm{g}$ for $60 \mathrm{~min}$ at $4^{\circ} \mathrm{C}$ to obtain the cytosolic supernatant. The mitochondrial and microsomal pellets were then redissolved in $800 \mu \mathrm{L}$ of a homogenization buffer and their protein con- tent was determined by the method of Bradford (25) using bovine serum albumin as the standard.

Lipid peroxidation and hydrogen peroxide assay

Lipid peroxidation levels were measured using plasma, erythrocyte (26) and hepatic thiobarbituric acid substances (TBARS) (27). Plasma and erythrocyte were mixed with 5\% trichloroacetic acid (TCA) and 60 $\mathrm{mmol} / \mathrm{L}$ thiobarbituric acid (TBA). After incubation at $80^{\circ} \mathrm{C}$ for $90 \mathrm{~min}$, the supernatants were centrifuged at $1000 \times \mathrm{g}$ for $15 \mathrm{~min}$ at $4^{\circ} \mathrm{C}$. The absorbance of the supernatant was determined at $535 \mathrm{~nm}$ using tetramethoxypropane (Sigma Chemical Co.) as the standard. Hepatic homogenates containing $8.1 \%$ sodium dodecyl sulfate were mixed with $20 \%(\mathrm{w} / \mathrm{v})$ acetic acid ( $\mathrm{pH} 3.5)$, distilled water and $0.8 \%(\mathrm{w} / \mathrm{v})$ TBA. The reaction mixture was heated at $95^{\circ} \mathrm{C}$ for $60 \mathrm{~min}$. After cooling the mixture, $n$-butanol:pyridine $(15: 1, \mathrm{v} / \mathrm{v})$ was added and centrifuged at $800 \times \mathrm{g}$ for $15 \mathrm{~min}$. The resulting colored layer was measured at $535 \mathrm{~nm}$. The hydrogen peroxide levels in erythrocyte and liver were measured by Wolff's method (28). FOX 1 (ferrous oxidation) reagent was prepared from $0.25 \mathrm{M} \mathrm{H}_{2} \mathrm{SO}_{4}, 1 \mathrm{M}$ sorbitol, $2.5 \mathrm{mM}$ ammonium iron (II), $1 \mathrm{mM}$ xylenol orange, and hydrogen peroxide levels were determined at $560 \mathrm{~nm}$ absorbance.

\section{Enzyme assays}

The SOD activity was measured according to the method of Marklund and Marklund (29) with a slight modification. One unit was determined as the amount of enzyme that inhibited the oxidation of pyrogallol by $50 \%$. The CAT activity was measured using Aebi's (30) method, in which the disappearance of hydrogen peroxide was monitored spectrophotometrically at $240 \mathrm{~nm}$ for 5 min using a spectrophotometer. The GSH-Px activity was measured using the spectrophotometric assay, as described previously by Paglia and Valentine's (31) methods with a slight modification. The reaction mixture included $30 \mathrm{mM}$ glutathione, $6 \mathrm{mM}$ NADPH and $\mathrm{H}_{2} \mathrm{O}_{2}$ in a $0.1 \mathrm{M}$ Tris- $\mathrm{HCl}(\mathrm{pH} 7.2)$ buffer. The reaction was initiated by adding the enzyme source and the absorbance was measured at $340 \mathrm{~nm}$ for $5 \mathrm{~min}$. The glutathione reductase (GR) activity was measured by monitoring the oxidation of NADPH at $340 \mathrm{~nm}$ (32). Plasma paraoxonase (PON) activity was assayed using the methods described by Mackness et al. (33), which measured the increase in absorbance for $60 \mathrm{sec}$ at $405 \mathrm{~nm}$ and $25^{\circ} \mathrm{C}$. The alcohol dehydrogenase (ADH) activity was measured by monitoring the formation of NADH at $340 \mathrm{~nm}$ in the hepatic cytosol (34). The aldehyde dehydrogenase (ALDH) activity in the mitochondria of liver was assayed using Koivula and Koivusalo's method (35). The activity of CYP2E1 was measured in microsome fraction of liver 
by the formation of 4-nitrocatechol detected spectrophotometically as previously described (36). The xanthine oxidase (XOD) activity was measured by monitoring the production of uric acid at $290 \mathrm{~nm}$ in plasma and liver (37).

\section{Plasma ethanol concentration}

Plasma ethanol concentration was determined using a commercial kit (ECET-100, BioAssay Systems, Hayward, CA, USA).

\section{Statistical analysis}

All data were presented as the mean \pm SE. Statistical analysis was carried out using SPSS statistical software (version 11.0, SPSS Inc., Chicago, IL, USA). Significant differences among the groups were determined by oneway ANOVA. Post-hoc Duncan's multiple-range tests
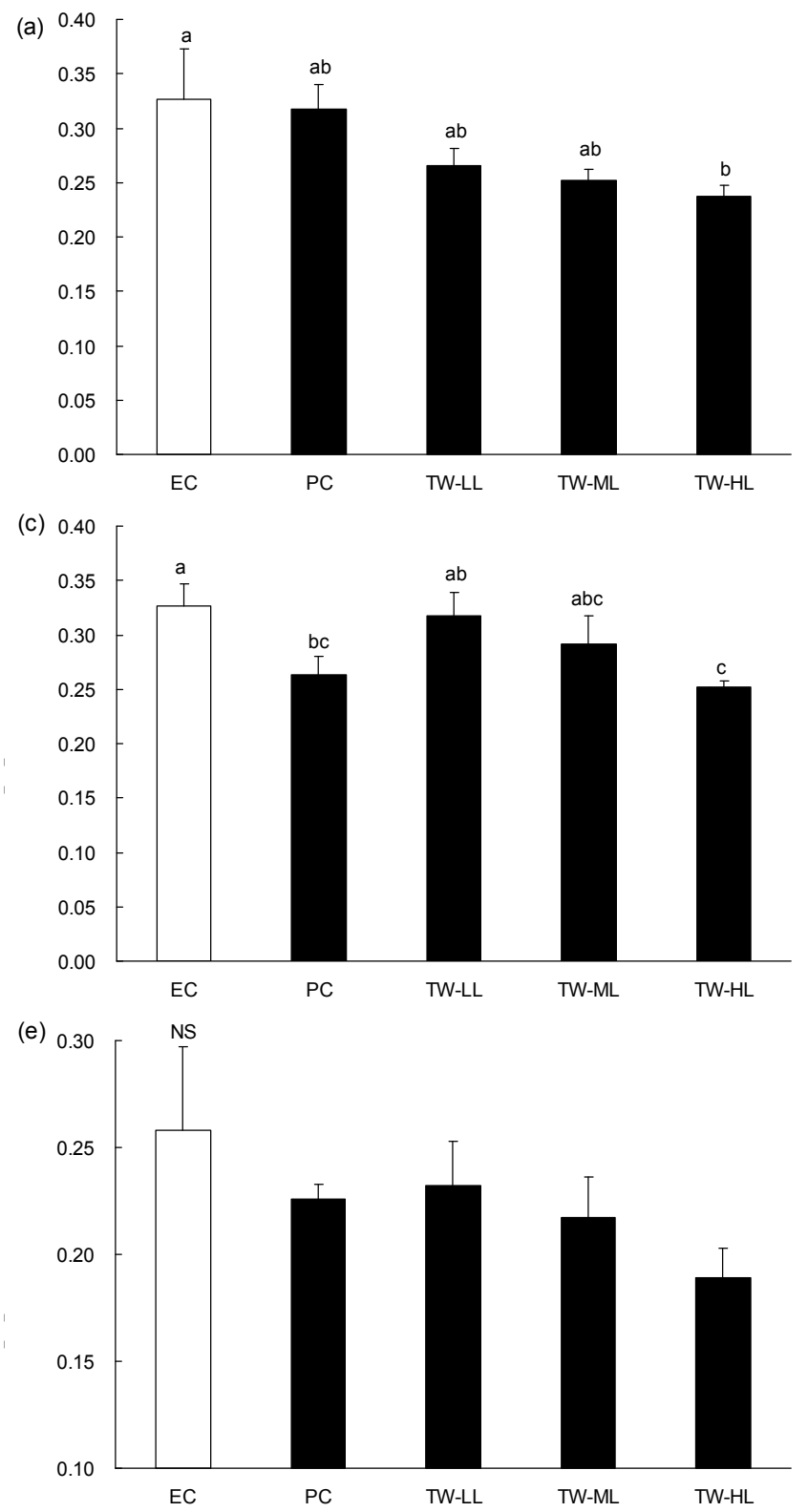

were performed when differences were identified between the groups. Significant differences were accepted at $\mathrm{p}<0.05$.

\section{RESULTS}

Effects of tomato wine with lycopene on plasma, erythrocyte and hepatic hydrogen peroxide and lipid peroxidation levels

In rats fed HFD plus varying lycopene content, erythrocyte and hepatic hydrogen peroxide level tended to be dose-dependently decreased compared to ethanol/ HFD-fed rats (Fig. 2). Plasma TBARS level was significantly decreased by tomato wine with high lycopene content compared to ethanol plus HFD diet. Supplementation of tomato wine over 6 weeks also decreased eryth-

(b)

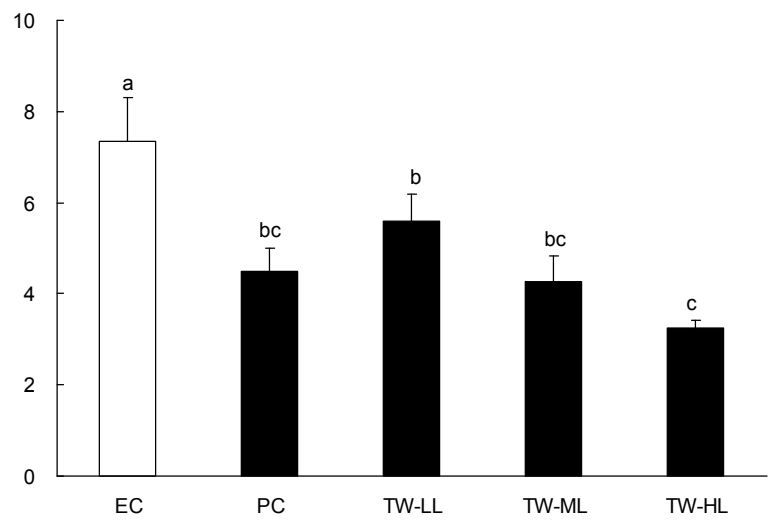

(d)

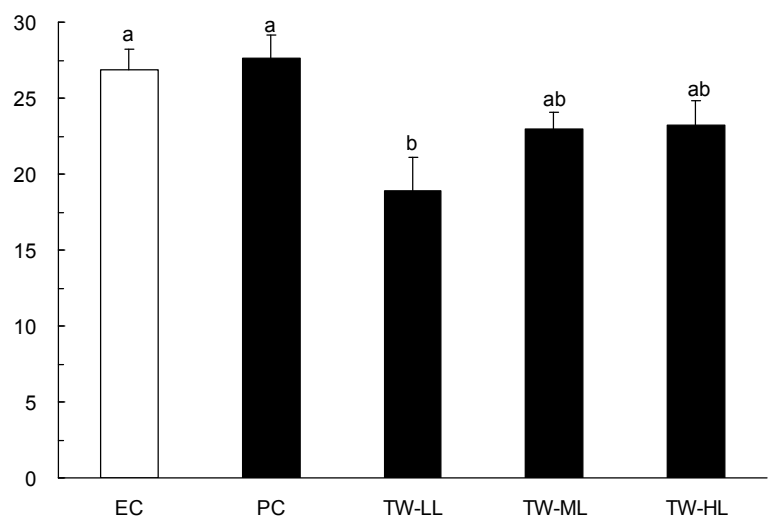

Fig. 2. Effects of tomato wine containing low, medium and high lycopene content on TBARS and hydrogen peroxide levels in plasma, erythrocyte and liver of HFD-fed rats. Values are mean $\pm \mathrm{SE} .{ }^{\mathrm{a}-\mathrm{c}}$ Means not sharing a common letter are significantly different among groups at $\mathrm{p}<0.05$. EC, ethanol control; PC, pair-fed control; TW-LL, tomato wine with low lycopene content; TW-ML, tomato wine with medium lycopene content; TW-HL, tomato wine with high lycopene content; $\mathrm{H}_{2} \mathrm{O}_{2}$, hydrogen peroxide; TBARS, thiobarbituric acid reactive substance. 
Table 2. Effects of tomato wine containing low, medium and high lycopene content on antioxidant enzyme activities in plasma, erythrocyte and liver of HFD-fed rats

\begin{tabular}{lccccc}
\hline Groups & EC & PC & TW-LL & TW-ML & TW-HL \\
\hline Liver & & & & \\
SOD (unit/mg protein) & $24.73 \pm 1.21^{\mathrm{b}}$ & $25.65 \pm 0.94^{\mathrm{b}}$ & $24.77 \pm 3.17^{\mathrm{b}}$ & $32.13 \pm 0.81^{\mathrm{b}}$ & $51.29 \pm 6.54^{\mathrm{a}}$ \\
CAT ( $\mu \mathrm{mol} / \mathrm{min} / \mathrm{mg}$ protein) & $2.79 \pm 0.67^{\mathrm{b}}$ & $6.19 \pm 0.57^{\mathrm{a}}$ & $5.93 \pm 0.63^{\mathrm{a}}$ & $5.94 \pm 0.50^{\mathrm{a}}$ & $6.07 \pm 0.51^{\mathrm{a}}$ \\
GSH-Px (nmol/min/mg protein) & $17.07 \pm 0.81$ & $19.69 \pm 1.95$ & $18.13 \pm 1.14$ & $18.09 \pm 0.71$ & $19.51 \pm 1.34$ \\
GR (nmol/min/mg protein) & $92.20 \pm 7.18$ & $111.74 \pm 12.70$ & $97.51 \pm 7.79$ & $99.58 \pm 6.48$ & $122.33 \pm 12.97$ \\
Erythrocyte & & & & \\
SOD (unit/mg Hb) & $0.29 \pm 0.02^{\mathrm{a}}$ & $0.23 \pm 0.02^{\mathrm{b}}$ & $0.26 \pm 0.02^{\mathrm{ab}}$ & $0.24 \pm 0.02^{\mathrm{ab}}$ & $0.21 \pm 0.01^{\mathrm{b}}$ \\
CAT ( $\mu \mathrm{mol} / \mathrm{min} / \mathrm{mg} \mathrm{Hb})$ & $0.182 \pm 0.015^{\mathrm{a}}$ & $0.108 \pm 0.014^{\mathrm{b}}$ & $0.133 \pm 0.017^{\mathrm{b}}$ & $0.132 \pm 0.014^{\mathrm{b}}$ & $0.108 \pm 0.008^{\mathrm{b}}$ \\
GSH-Px $(\mathrm{nmol} / \mathrm{min} / \mathrm{mg} \mathrm{Hb})$ & $55.51 \pm 3.54^{\mathrm{a}}$ & $34.66 \pm 2.32^{\mathrm{b}}$ & $52.42 \pm 5.84^{\mathrm{a}}$ & $49.50 \pm 6.34^{\mathrm{ab}}$ & $35.56 \pm 2.34^{\mathrm{b}}$ \\
GR (nmol/min/mg Hb) & $116.95 \pm 12.50^{\mathrm{a}}$ & $90.29 \pm 12.83^{\mathrm{ab}}$ & $108.56 \pm 15.56^{\mathrm{a}}$ & $90.53 \pm 13.53^{\mathrm{ab}}$ & $52.30 \pm 8.81^{\mathrm{b}}$ \\
Plasma & & & & \\
PON $(\mu \mathrm{mol} / \mathrm{min} / \mathrm{mL})$ & $0.163 \pm 0.008^{\mathrm{a}}$ & $0.150 \pm 0.006^{\mathrm{ab}}$ & $0.137 \pm 0.014^{\mathrm{abc}}$ & $0.116 \pm 0.010^{\mathrm{c}}$ & $0.128 \pm 0.006^{\mathrm{bc}}$ \\
\hline
\end{tabular}

Values are mean $\pm \mathrm{SE}$.

${ }^{\mathrm{a}-\mathrm{c}}$ Means not sharing a common letter in a row are significantly different among groups at $\mathrm{p}<0.05$.

EC, ethanol control; PC, pair-fed control; TW-LL, tomato wine with low lycopene content; TW-ML, tomato wine with medium lycopene content; TW-HL, tomato wine with high lycopene content; SOD, superoxide dismutase; CAT, catalase; GSH-Px, glutathion peroxidase; GR, glutathione reductase; PON, paraoxonase.

rocyte TBARS levels in HFD-fed rats compared to ethanol/HFD-fed rats, but not pair-fed rats. Notably, tomato wine with high lycopene content appeared to be more effective at suppression of plasma and erythrocyte TBARS than tomato wine with lower lycopene content. However, there was no dose dependent effect of lycopene content on hepatic TBARS. Hepatic TBARS level was significantly lowered in tomato wine with low lycopene content than in both ethanol/HFD-fed rats and pair-fed rats.

Effects of tomato wine with lycopene on antioxidant and pro-oxidant enzyme activities

Next, we compared how the ethanol/HFD diet vs. the isocaloric control diet influences plasma, erythrocyte and hepatic antioxidant enzyme activities, and determined whether tomato wine with varying lycopene can regulate these antioxidant enzyme activities in plasma, erythrocyte and liver of HFD-fed rats (Table 2). Supplementation of tomato wine in HFD-fed rats over 6 weeks effectively increased hepatic SOD and CAT activities compared to the ethanol/HFD control group. Among the tomato wines tested, high lycopene induced the strongest response by increasing hepatic SOD and CAT activities. There were no differences in the hepatic GSH-Px and GR activities among groups.

In contrast to hepatic antioxidant activities, ethanol/ HFD-fed rats showed higher activities of erythrocyte SOD, CAT, GSH-Px and GR compared to the pair-fed control group and tomato wine containing lycopene dosedependently decreased these erythrocyte antioxidant enzyme activities compared to ethanol/HFD control group (Table 2). Plasma PON activity was also significantly lowered in rats fed tomato wine with medium or high lycopene content.

To further examine whether supplementation of tomato wine with lycopene inhibits pro-oxidant enzymes, we determined plasma and hepatic XOD activities (Fig. 3). The plasma XOD activity was increased in ethanol/ HFD-fed rats compared to pair-fed rats, whereas supplementation of tomato wine with medium or high lycopene content appeared to significantly inhibit plasma XOD activity compared to ethanol/HFD-fed rats. Hepatic XOD activity was not significantly different between pair-fed controls and HFD-fed rats regardless of the lycopene content of tomato-wine.

Effects of tomato wine with lycopene on plasma ethanol concentration and hepatic alcohol-metabolizing enzyme activities

We next investigated the potential effects of tomato wine with lycopene on plasma ethanol concentration and hepatic alcohol-metabolizing enzyme activities in HFDfed rats. Tomato wine with varying lycopene content dose-dependently lowered ethanol concentration in the plasma when compared among the ethanol-treated groups (Table 3). No ethanol was detected in the plasma from the pair-fed rats (Table 3). Hepatic ADH activity was not significantly different between ethanol/HFD rats and pair-fed controls, whereas hepatic ALDH activity was significantly higher in the ethanol/HFD-fed rats compared to pair-fed controls (Table 3). Supplementation of tomato wine with varying doses of lycopene resulted in increases of hepatic ADH and ALDH activities compared to ethanol/HFD-fed rats (Table 3). The activity of hepatic CYP2E1, another enzyme involved in ethanol metabolism, was not significantly different among groups (Fig. 3). 

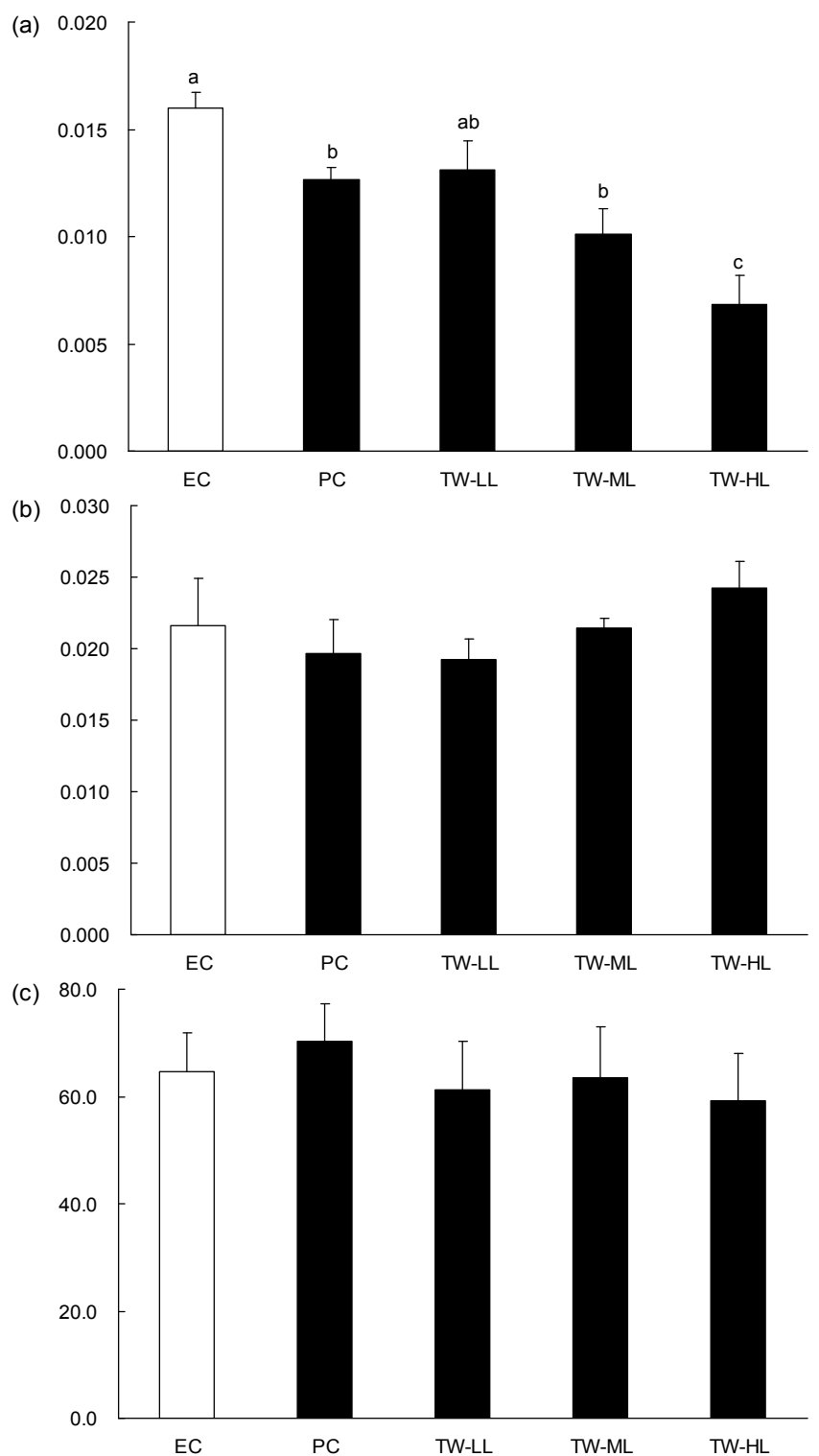

Fig. 3. Effects of tomato wine containing low, medium and high lycopene content on XOD and CYP2E1 activities in plasma and liver of HFD-fed rats. Values are mean \pm SE. ${ }^{\mathrm{a}-\mathrm{c}}$ Means not sharing a common letter are significantly different among groups at $\mathrm{p}<0.05$. EC, ethanol control; PC, pair-fed control; TW-LL, tomato wine with low lycopene content; TW-ML, tomato wine with medium lycopene content; TW-HL, tomato wine with high lycopene content; XOD, xanthine oxidase; CYP2E1, cytochrome P450-2E1.

\section{DISCUSSION}

Oxidative stress is characterized by an imbalance between ROS generation and antioxidant capacity. ROS are naturally generated in small amounts through normal metabolic reactions and are constantly produced and eliminated, since cells have endogenous antioxidant capacity. However, overproduction of ROS can cause damage to lipids, proteins and DNA, which can then induce pathological events leading to hepatic steatosis, cardiovascular diseases and cancer. It is well known that chronic and excessive alcohol consumption can promote the generation of ROS through the various pathways related to ethanol metabolism. Ethanol is extensively oxidized into acetaldehyde by the ADH and then into acetate by ALDH in the liver. Acetaldehyde is a highly toxic metabolite of ethanol and the accumulation of acetaldehyde in the liver after chronic alcohol consumption has been implicated in the pathogenesis of alcoholic liver disease (3). In the current study, alcohol feeding led to inhibition of hepatic ALDH, but not ADH, compared to pair-fed rats. This result indicates that moderate alcohol intake in combination with an HFD over 6 weeks can be efficiently converted into acetaldehyde by normal ADH activity but the subsequent conversion of acetaldehyde into acetate can be delayed due to low ALDH activity. Interestingly, supplementation of tomato wine with lycopene effectively activated both ADH and ALDH activities in HFD-fed rats, thereby enabling the conversion of ethanol into acetate via acetaldehyde and contributing to a lower plasma ethanol concentration.

Acetaldehyde is also oxidized into acetate by XOD in liver, producing superoxide and hydrogen peroxide $(38,39)$. However, others have previously demonstrated that XOD does not play a major role in oxygen radical production in the liver during acute alcohol intoxication (40). Our present study also showed that hepatic XOD activity was not significantly different between pair-fed controls and alcohol-fed rats regardless of lycopene content of tomato-wine. Furthermore, we observed no effect of moderate alcohol consumption in HFD-fed rats on

Table 3. Effects of tomato wine containing low, medium and high lycopene content on plasma ethanol concentration and hepatic alcohol metabolizing enzyme activities in HFD-fed rats

\begin{tabular}{llcccc}
\hline & \multicolumn{4}{c}{ Groups } \\
\cline { 2 - 5 } & \multicolumn{1}{c}{ EC } & PC & TW-LL & TW-ML & TW-HL \\
\hline Ethanol (mg/dL) & $6.59 \pm 0.82^{\mathrm{a}}$ & - & $4.52 \pm 0.54^{\mathrm{ab}}$ & $3.35 \pm 0.94^{\mathrm{b}}$ & $3.00 \pm 0.60^{\mathrm{b}}$ \\
Alcohol dehydrogenase (nmol/min/mg protein) & $6.85 \pm 0.11^{\mathrm{abc}}$ & $6.25 \pm 0.59^{\mathrm{bc}}$ & $7.83 \pm 0.31^{\mathrm{ab}}$ & $6.07 \pm 0.60^{\mathrm{c}}$ & $8.19 \pm 0.88^{\mathrm{a}}$ \\
Aldehyde dehydrogenase (nmol/min/mg protein) & $1.16 \pm 0.36^{\mathrm{b}}$ & $5.21 \pm 0.89^{\mathrm{a}}$ & $5.42 \pm 0.50^{\mathrm{a}}$ & $6.31 \pm 1.93^{\mathrm{a}}$ & $4.84 \pm 0.97^{\mathrm{a}}$ \\
\hline
\end{tabular}

Values are mean $\pm \mathrm{SE}$.

${ }^{\mathrm{a}-\mathrm{c}}$ Means not sharing a common letter in a row are significantly different among groups at $\mathrm{p}<0.05$.

EC, ethanol control; PC, pair-fed control; TW-LL, tomato wine with low lycopene content; TW-ML, tomato wine with medium lycopene content; TW-HL, tomato wine with high lycopene content; ADH, alcohol dehydrogenase; ALDH, aldehyde dehydrogenase. 
hepatic CYP2E1 activity, which also helps oxidize ethanol particularly following chronic alcohol intake $(41,42)$, compared to pair-fed controls and tomato wine with lycopene-supplemented groups. An in vitro study showed that lycopene attenuated alcoholic induced-oxidative stress and apoptosis in HepG2 cells overexpressing CYP2E1 (17). In contrast, in vivo supplementation of lycopene at a high dose $(3.3 \mathrm{mg} / \mathrm{kg} \mathrm{BW} /$ day $)$, but not lower dose $(1.1 \mathrm{mg} / \mathrm{kg} \mathrm{BW} /$ day $)$ is reported to significantly induce hepatic CYP2E1 levels and inflammation in alcohol-fed rats (21), suggesting a need for caution among individuals consuming high amounts of both alcohol and lycopene. Some variation among published reports regarding the potency of lycopene on CYP2E1related oxidative stress may be due to many factors such as species, dietary intervention period, lycopene source and amount of alcohol.

On the other hand, alcohol feeding over 6 weeks resulted in significantly lowered activity of hepatic CAT, antioxidant enzyme, compared to pair-fed group in the present study as previously observed by others (40). In contrast, supplementation of tomato wine containing lycopene appeared to effectively activate hepatic SOD and CAT activities compared to ethanol plus HFD group. Furthermore, we observed a trend of decreased hepatic lipid peroxidation with tomato wine containing lycopene in HFD-fed rats. Antioxidant enzymes such as SOD, CAT and GSH-Px are important in protecting cells from oxidative damage. SOD converts superoxide radicals into hydrogen peroxide, which is then further metabolized by CAT, which catalyzes the conversion of hydrogen peroxide to water and oxygen. If CAT activity is not sufficiently enhanced to metabolize hydrogen peroxide, this can lead to increased hydrogen peroxide and TBARS levels (43). Our results are consistent with the study by Hsu et al. (44), who demonstrated that supplementation with tomato paste containing lycopene for 8 weeks increased hepatic SOD, CAT and GSH-Px activities and decreased lipid peroxidation in cholesterol-fed hamsters. However, in the current study, there were no dose-dependent effects of lycopene content on TBARS levels in liver, suggesting that the low dose of lycopene contained in tomato wine was sufficient to suppress hepatic lipid TBARS levels. Taken together, our findings indicate that tomato wine and lycopene supplementation may suppress hepatic lipid peroxidation by activating antioxidant enzymes as well as by suppressing pro-oxidant enzymes such as ADH and ALDH in liver of HFD-fed rats.

Erythrocytes are also susceptible to lipid peroxidation due to alcohol consumption (45), and we found that alcohol feeding significantly increased erythrocyte TBARS and hydrogen peroxide levels concomitant with increased activities of hepatic antioxidant enzymes like SOD, CAT, GSH-Px and GR compared to pair-fed rats. Accordingly, our study suggests that the combination of alcohol and an HFD may result in overproduction of ROS-stimulating antioxidant enzyme activity to cope with the increased lipid peroxidation in erythrocytes. Interestingly, the erythrocyte lipid peroxidation and antioxidant enzyme activities were recovered to the normal level in all mice on tomato wine with lycopene. Notably, tomato wine with high lycopene content appeared to be the most effective at suppressing the increase in erythrocyte lipid peroxidation and antioxidant enzyme activities in HFD fed rats, suggesting that the lycopene content, rather than other functional components in tomato wine, was primarily responsible for suppression of oxidative stress induced by ethanol. Bose and Agrawal (4648) also showed that tomato or lycopene decreased erythrocyte lipid peroxidation levels in patients with cardiovascular disease and type 2 diabetes.

Zima et al. (49) reported that ethanol significantly increases plasma XOD activity in both rats and hamsters, suggesting that plasma XOD may be a sensitive marker of liver damage. In our study, we found that plasma XOD activity was higher in alcohol-fed group compared to pair-fed group, whereas all mice on tomato wine with varying lycopene content markedly decreased the activity of plasma XOD. Furthermore, tomato wine with lycopene effectively suppressed plasma lipid peroxidation levels, indicated by significantly lower plasma TBARS in these rats. Previous studies also supported a role for tomato products in the prevention of plasma lipid peroxidation $(50,51)$. Plasma PON, an HDL-associated antioxidant enzyme (52), protects against plasma lipid oxidation (53). In general, PON activity was suggested to be inversely associated with oxidative stress in plasma (54) and antioxidants can increase PON activity (55). However, two previous studies reported that a high intake of vegetables rich in vitamins $\mathrm{E}$ and $\mathrm{C}$ was negatively correlated with serum PON activity in Finnish populations $(56,57)$. We also showed that tomato wine and lycopene supplementation in HFD-fed rats resulted in lower plasma PON activity compared to ethanol/ HFD-fed rats. There was no effect of ethanol on plasma PON activity compared to the pair-fed group. This finding is in accordance with previous experimental data showing no association between alcohol consumption and serum PON activity in healthy men (58).

In conclusion, the present study suggests that supplementation of tomato wine with varying lycopene content protects against alcohol-induced oxidative stress in HFD-fed rats. Tomato wine with high lycopene content 
appeared to be more effective than tomato wine with lower lycopene content for suppressing lipid peroxidation. The beneficial effects of tomato wine appear to be partly mediated through regulation of pro-oxidant and antioxidant enzyme activity in plasma, erythrocyte and liver. Thus, supplementation of tomato wine fortified with lycopene could prove promising in decreasing alcohol-induced hepatic steatosis and cardiovascular disease.

\section{ABBREVIATIONS}

$\mathrm{ADH}$, alcohol dehydrogenase; ALDH, aldehyde dehydrogenase; CAT, catalase; CYP2E1, cytochrome P4502E1; GSH-Px, glutathion peroxidase; GR, glutathione reductase; HFD, high fat diet; $\mathrm{H}_{2} \mathrm{O}_{2}$, hydrogen peroxide; PON, paraoxonase; ROS, reactive oxygen species; SOD, superoxide dismutase; TBA, thiobarbituric acid; TBARS, thiobarbituric acid-reactive substance; XOD, xanthine oxidase

\section{ACKNOWLEDGEMENTS}

This work was supported by the National Research Foundation of Korea (NRF) grant funded by the Korea government (No. 2011-0000912) and Kyungpook National University Research Fund 2007. None of the authors had any conflicts of interest.

\section{REFERENCES}

1. An JH. 2009. Proteomic analysis of the protective effects of Platycodi Radix in liver of chronically alcoholic rats. $J$ Med Food 12: 1190-1198.

2. Lieber CS. 1991. Hepatic metabolic and toxic effect of ethanol. Alcohol Clin Exp Res 5: 573-592.

3. Liber CS. 1994. Alcohol and the liver. Hepatology 106: 1085-1105.

4. Demoria I, Vocia A, Fugassaa E, Burlandob B. 2006. Combined effects of high-fat diet and ethanol induce oxidative stress in rat liver. Alcohol 40: 185-191.

5. Renaud S. 1992. Wine, alcohol, platelets, and the French paradox for coronary heart disease. Lancet 339: 15231526

6. Lieber CS. 2004. Alcoholic fatty liver: its pathogenesis and mechanism of progression to inflammation and fibrosis. Alcohol 34: 9-19.

7. Alshatwi AA. 2010. Tomato powder is more protective than lycopene supplement against lipid peroxidation in rats. Nutr Res 30: 66-73.

8. Oshima S, Ojima F, Sakamoto H, Ishiguro Y, Terao J. 1996. Supplementation with carotenoids inhibits singletoxygen-mediated oxidation of human plasma low-density lipoprotein. J Agric Food Chem 44: 2306-2309.

9. Nguyen ML, Schwartz SJ. 1999. Lycopene: chemical and biological properties. Food Technol 53: 38-45.

10. Subhash C, Bose K, Agrawal BK. 2006. Effect of lycopene from cooked tomatoes on serum antioxidant enzymes, lipid peroxidation rate, lipid profile and glycated hemoglobin in type 2 diabetes. Indian J Nutr Diet 43: 153-160.

11. Di MP, Devasagayam TP, Kaiser S, Sies H. 1990. Carotenoids, tocopherols and thiols as biological singlet molecular oxygen quenchers. Biochem Soc Trans 18: 1054-1056.

12. Agarwal S, Rao AV. 1998. Tomato lycopene and low density lipoprotein oxidation: a human dietary intervention study. Lipids 33: 981-984.

13. Rao AV, Agarwal S. 1999. Role of lycopene as antioxidant carotenoids in the prevention of chronic diseases. Nutr Res 19: $305-323$.

14. Khachik F, Carvalho L, Bernstein PS. 2002. Chemistry, distribution, and metabolism of tomato carotenoids and their impact on human health. Exp Biol Med 227: 845-851.

15. Upritchard JE, Sutherland WH, Mann JI. 2000. Effect of supplementation with tomato juice, vitamin $\mathrm{E}$, and vitamin $\mathrm{C}$ on LDL oxidation and products of inflammatory activity in type 2 diabetes. Diabetes Care 23: 733-738.

16. Kiokias S, Gordon MH. 2003. Dietary supplementation with a natural carotenoid mixture. Eur J Clin Nutr 57: $1135-1140$.

17. Xu Y, Leo MA, Lieber CS. 2003. Lycopene attenuates alcoholic apoptosis in HepG2 cells expressing CYP2E1. Biochem Biophys Res Commun 308: 614-618.

18. Sugiura M, Nakamura M, Ikoma Y, Yano M, Ogawa K, Matsumoto H, Kato M, Ohshima M, Nagao A. 2005. High serum carotenoids are inversely associated with serum gamma-glutamyltransferase in alcohol drinkers within normal liver function. $J$ Epidemiol 15: 180-186.

19. Lowe GM, Booth LA, Young AJ, Bilton RF. 1999. Lycopene and beta-carotene protect against oxidative damage in HT29 cells at low concentrations but rapidly lose this capacity at higher doses. Free Radic Res 30: 141-151.

20. Yeh S, Hu M. 2000. Antioxidant and pro-oxidant effects of lycopene in comparison with beta-carotene on oxidant-induced damage in Hs68 cells. $J$ Nutr Biochem 11: 548-554

21. Veeramachaneni S. 2008. High dose lycopene supplementation increases hepatic cytochrome P4502E1 protein and inflammation in alcohol-fed rats. J Nutr 138: 13291335.

22. Lieber CS, DeCarli LM. 1986. The feeding of ethanol in liquid diets. Alcohol Clin Exp Res 10: 550-553.

23. McCord JM, Fridovich I. 1969. Superoxide dismutase. An enzymic function for erythrocuprein (hemocuprein). J Biol Chem 244: 6049-6055.

24. Hulcher FH, Oleson WH. 1973. Simplified spectrophotometric assay for microsomal 3-hydroxy-3-methylglutaryl CoA reductase by measurement of coenzyme A. J Lipid Res 14: 625-631.

25. Bradford MM. 1976. A rapid and sensitive method for the quantitation of microgram quantities of protein utilizing the principle of protein-dye binding. Anal Biochem 72: 248-254.

26. Basil G, Tarladgis AM, Pearson LR, Dugan J. 1964 Chemistry of the 2-thiobarbituric acid test for etermination of oxidative rancidity in foods. II. formation of the tba-malonaldehyde complex without acid-heat treatment. $J \mathrm{Sci}$ Food Agric 15: 602-607.

27. Ohkawa H, Ohishi N, Yagi K. 1979. Assay for lipid peroxides in animal tissues by thiobarbituric acid reaction. Anal Biochem 95: 351-358.

28. Wolff SP. 1994. Ferrous ion oxidation in presence of ferric ion indicator xylenol orange for measurement of hydroperoxides. Methods Enzymol 233: 182-189. 
29. Marklund S, Marklund G. 1974. Involvement of the superoxide anion radical in the autoxidation of pyrogallol and a convenient assay for superoxide dismutase. Eur J Biochem 47: 469-474.

30. Aebi H. 1974. Catalase. In Method of Enzymatic Analysis. Academic Press, New York, NY, USA. p 2, 673-684.

31. Paglia ED, Valentine WN. 1979. Studies on the quantitative and qualitative characterization of erythrocytes glutathione peroxidase. J Lab Clin Med 70: 158-169.

32. Pinto RE, Bartley W. 1969. The effect of age and sex on glutathione reductase and glutathione peroxidase activities and on aerobic glutathione oxidation in rat liver homogenates. Biochem $J$ 112: 109-115.

33. Mackness MI, Harty D, Bhatnagar D, Winocour PH, Arrol S, Ishola M, Durrington PN. 1991. Serum paraoxonase activity in familial hypercholesterolaemia and insulin-dependent diabetes mellitus. Atherosclerosis 86: 193-199.

34. Rackerr E. 1950. Crystalline alcohol dehydrogenase from baker's yeast. J Biol Chem 184: 313-319.

35. Koivula T, Koivusalo M. 1975. Different form of rat liver aldehyde dehydrogenase and their subcellular distribution. Biochim Biophys Acta 397: 9-23.

36. Peng RX, Wang YS, Lei SB, Fu LS, Chen JH, Li QX. 1994. Characterization of monooxygenase system in Chinese fetal adrenal gland. Asian Pac J Pharmacol 9: 195-200.

37. Stirpe F, Della Corte E. 1969. The regulation of rat liver xanthine oxidase. $J$ Biol Chem 244: 3855-3863.

38. Halliwell B, Gutteridge JMC. 1990. Role of free radicals and catalytic metal ions in human disease. Methods Enzymol 186: 1-85.

39. Hippeli S, Elstner EF. 1997. OH-radical-type reactive oxygen species: a short review on the mechanisms of OH-radical and peroxynitrite toxicity. Z Naturforsch 52C: 555563.

40. Ribiere C, Sinaceur J, Sabourault D, Nordmann R. 1985. Hepatic catalase and superoxide dismutases after acute ethanol administration in rats. Alcohol 2: 31-33.

41. Liber CS, DeCarli LM. 1970. Hepatic microsomal ethanol-oxidizing system. In vitro characteristics and adaptive properties in vivo. $J$ Biol Chem 245: 2505-2512.

42. Lieber CS. 1997. Cytochrome P-4502E1: its physiological and pathological role. Physiol Rev 77: 517-544.

43. Haron D. 1991. The aging: Major risk factor for disease and death. Proc Natl Acad Sci USA 88: 5360-5364.

44. Hsu YM, Lai CH, Chang CY, Fan CT, Chen CT, Wu CH. 2008. Characterizing the lipid-lowering effects and antioxidant mechanisms of tomato paste. Biosci Biotechnol Biochem 72: 677-685.

45. Lindi C, Montorfano G, Marciani P. 1998. Rat erythrocyte susceptibility to lipid peroxidation after chronic ethanol intake. Alcohol Alcohol 16: 311-316.

46. Bose KS, Agrawal BK. 2006. Effect of long term supple- mentation of tomatoes (cooked) on levels of antioxidant enzymes, lipid peroxidation rate, lipid profile and glycated haemoglobin in type 2 diabetes mellitus. West Indian Med $J$ 55: 274-278.

47. Bose KS, Agrawal BK. 2007. Effect of lycopene from cooked tomatoes on serum antioxidant enzymes, lipid peroxidation rate and lipid profile in coronary heart disease. Singapore Med J 48: 415-420.

48. Bose KS, Agrawal BK. 2007. Effect of lycopene from tomatoes (cooked) on plasma antioxidant enzymes, lipid peroxidation rate and lipid profile in grade-I hypertension. Ann Nutr Metab 51: 477-481.

49. Zima T, Novák L, Stípek S. 1993. Plasma xanthine oxidase level and alcohol administration. Alcohol Alcohol 28: 693-694.

50. Bub A, Watzl B, Abrahamse L, Delincee H, Adam S, Wever J, Muller H, Rechkemmer G. 2000. Moderate intervention with carotenoid-rich vegetable products reduces lipid peroxidation in men. J Nutr 130: 2200-2206.

51. Visioli F, Riso P, Grande S, Galli C, Porrini M. 2003. Protective activity of tomato products on in vivo markers of lipid oxidation. Eur $J$ Nutr 42: 201-206.

52. Mackness MI, Mackness B, Durrington PN, Fogelman AM. 1998. Paraoxonase and coronary heart disease. Curr Opin Lipidol 9: 319-324.

53. Rosenblat M, Grunfeld O, Hayek T, Aviram M. 2002. Serum paraoxonase activity and the extent of lipid peroxidation are not affected by increased levels of human apolipoprotein A-I: studies in transgenic mice. Clin Chem Lab Med 40: 9-14.

54. Rozenberg O, Rosenblat M, Coleman R, Shih DM, Aviram M. 2003. Paraoxonase (PON1) deficiency is associated with increased macrophage oxidative stress: studies in PON1-knockout mice. Free Radic Biol Med 34: 774-784

55. Hayek T, Fuhrman B, Vaya J, Rosenblat M, Belinky P, Coleman R. 1997. Reduced progression of atherosclerosis in apolipoprotein E-deficient mice following consumption of red wine, or its polyphenols quercetin or cetechin, is associated with educed susceptibility of LDL to oxidation and aggregation. Arterioscler Thromb Vasc Biol 17: 27442752.

56. Rantala M, Silaste ML, Tuominen A, Kaikkonen J, Salonen JT, Alfthan G. 2002. Dietary modifications and gene polymorphisms alter serum paraoxonase activity in healthy women. J Nutr 132: 3012-3017.

57. Kleemola P, Freese R, Jaulainen M, Pahlman R, Alfthan G, Mutanen M. 2002. Dietary determinants of serum paraoxonase activity in healthy humans. Atherosclerosis 160: 425-432.

58. Sarandöl E, Serdar Z, Dirican M, Safak O. 2003. Effects of red wine consumption on serum paraoxonase/arylesterase activities and on lipoprotein oxidizability in healthy men. J Nutr Biochem 14: 507-512. 